\title{
Karakteristik Fisik dan Identifikasi Senyawa pada Minyak Atsiri dari Limbah Kulit Jeruk
}

\author{
Physical Characteristics and Compounds Identification in Essential Oils of Orange \\ Peel Waste
}

\author{
Author(s): Imro'ah Ikarini ${ }^{(1) * ;}$ Harwanto $^{(1)}$; Yunimar ${ }^{(1)}$ \\ (1) Balai Penelitian Tanaman Jeruk dan Buah Subtropika, Kementerian Pertanian \\ * Corresponding author: imroahikarini@gmail.com
}

\begin{abstract}
ABSTRAK
Teknologi Pascapanen untuk meningkatkan nilai tambah produk jeruk dapat dilakukan dengan memanfaatkan limbah kulit jeruk menjadi minyak atsiri atau essential oil. Kulit jeruk mengandung minyak atsiri, telah banyak dimanfaatkan oleh industri kimia seperti parfum, sebagai penambah aroma jeruk pada minuman dan makanan. Pada penelitian ini dilakukan karakterisasi fisik dan kimia serta kandungan senyawa volatil pada minyak atsiri kulit jeruk purut dan jeruk siam pontianak. Penelitian ini merupakan penelitian deskriptif eksploratif menggunakan minyak atsiri kulit buah jeruk yang diperoleh dengan metode distilasi. Hasil uji GC-MS menunjukkan bahwa pada sampel minyak atsiri jeruk purut dapat teridentifikasi 9 senyawa dan minyak atsiri jeruk siam pontianak teridentifikasi 4 senyawa, dimana keduanya sama-sama mengandung senyawa limonin. Hasil rata-rata perhitungan rendemen minyak atsiri jeruk purut dan siam pontianak berturut-turut adalah 4,369\% dan 3,161\%. Minyak atsiri jeruk purut dan siam Pontianak, masing-masing memiliki karakteristik yang berbeda pada parameter putaran optik, warna fisik, serta uji organoleptik warna dan aroma.
\end{abstract}

\section{Kata Kunci:}

distilasi, GC-MS, jeruk purut, minyak atsiri, siam Pontianak$$
\text { ABSTRACT }
$$

Keywords: Postharvest technology to increase the value-added of citrus products can be distillation, accomplished by utilizing orange peel waste produced into essential oils. Orange peel $G C-M S$, containing essential oil has been widely used by the chemical industry such as perfume,

kaffir lime,

essential oil, siam Pontianak as an enhancer of citrus aroma in food and beverages. In this study, physical and chemical characterization as well as identification of volatile compounds contained in the essential oil of kaffir lime and siam Pontianak peel was carried out. This is an exploratory descriptive study using essential oil of citrus peel obtained by the distillation method. Results of GC-MS test showed that 9 compounds were identified in the samples of kaffir lime essential oil and 4 compounds were identified in Pontianak Siamese essential oil, both of which contained limonin compounds. The average results of yield calculation of kaffir lime and Pontianak Siamese essential oils were $4.369 \%$ and $3.161 \%$, respectively. Kaffir lime and Pontianak Siamese essential oils have different characteristics on the optical rotation parameters, physical color, as well as organoleptic tests on the color and aroma.
\end{abstract}




\section{PENDAHULUAN}

Harga buah jeruk yang rendah akibat melimpahnya produksi buah ketika panen raya membuat petani rugi. Penumpukan buah jeruk saat panen raya menyebabkan banyak buah yang rusak dan terbuang. Oleh karena itu, saat ini telah berkembang pengolaha pascapanen buah jeruk menjadi produk turunan pangan seperti minuman sari buah, es krim, selai dan aneka keripik (Honestin et al., 2020; Ikarni et al., 2020) Pengolahan pascapanen tersebut memanfaatkan bagian daging buah jeruk, sehingga kulit jeruk terbuang dan dianggap sebagai limbah.

Kulit jeruk mengandung senyawa aromatik sehingga dapat dimanfaatkan menjadi minyak atsiri (Fekadu et al., 2019). Minyak atsiri saat ini banyak dimanfaatkan sebagai bahan tambahan pada makanan, ditambahkan sebagai penambah aroma pada makanan dan produk non pangan, sebagai anti bakteri, dan sebagai campuran pada berbagai produk farmasi (Espina et al., 2011; ManiLópez et al., 2017). Minyak atsiri kulit jeruk mengandung komponen diantaranya limonin, $\beta$-pinene, linalool, linalyl acetate dan masih banyak yang lain (Arce et al., 2005; Sawamura et al., 2006). Diantara senyawa tersebut, yang biasanya paling banyak terkandung dalam minyak atsiri adalah limonin (Kurniawan et al., 2008).

Pengolahan minyak atsiri pada kulit jeruk dapat dilakukan dengan berbagai metode seperti distilasi atau penyulingan, pengepresan, ekstraksi dengan microwave (Kartika Fitri \& Proborini, 2018). Metode distilasi yang sering digunakan adalah distilasi uap-air dan distilasi air (water distillation). Metode water distillation bahan secara langsung dikontakkan dengan air mendidih (Kurniawan et al., 2008). Hasil dari proses distilasi adalah minyak yang bercampur dengan air. Campuran tersebut dapat dipisahkan menggunakan labu atau corong pemisah.
Jeruk purut biasanya hanya dimanfaatkan bagian daun nya, sehingga buah jeruk purut banyak yang dibiarkan busuk di pohon atau dipanen untuk dibuang. Pada jeruk siam pontianak pemanfaatkan saat ini masih terbatas untuk diambil daging buahnya, sehingga kulit buah yang berpotensi untuk diolah belum banyak dimanfaatkan. Oleh karena itu pada penelitian ini, memanfaatkan kulit buah jeruk purut dan kulit buah jeruk siam Pontianak sebagai minyak atsiri. Minyak atsiri yang telah diperoleh dari proses distilasi, dapat diuji karakteristik fisik dan kimia nya. Pengujian karakteristik ini dilakukan untuk menentukan mutu dan kualitas dari minyak atsiri yang dihasilkan. Kandungan senyawa kimia pada minyak atsiri dapat dianalisa menggunakan GCMS. Penelitian ini bertujuan untuk mengetahui karakteristik fisik dan kandungan senyawa pada minyak atsiri yang diperoleh dari distilasi kulit jeruk purut dan jeruk siam Pontianak.

\section{METODOLOGI}

Penelitan dilaksanakan di laboratrium pascapanen, Balai Penelitian Tanaman Jeruk dan Buah Subtropika, Batu Jawa Timur. Bahan yang digunakan dalam penelitian ini adalah, jeruk purut dan jeruk siam pontianak, aquades, alkohol $70 \%$, alkohol 80\%. Jumlah sampel adalah sebanyak 30. Proses distilasi kulit jeruk menggunakan metode water distillation dengan pelarut aquades dengan waktu distilasi selama 2 jam. Distilasi menggunakan seperangkat alat distilasi yaitu labu alas bulat kapasitas 2 liter, kondensor, termometer, penyangga, pompa air, ice pack, labu penampung minyak, dan corong pisah. Variabel yang diamati dalam penelitian ini adalah, rendemen, bobot jenis, warna, indeks putaran optik, uji sensori kesukaan warna dan aroma, dan kandungan senyawa volatil menggunakan GC-MS. Pengujian GC-MS menggunakan instrument GC-MS (QP- 
2010 Ultra Shimadzu, jenis kolom Rtx.1m, optimasi suhu $40-250{ }^{\circ} \mathrm{C}$. Penelitian ini menggunakan metode deskriptif..

\section{HASIL DAN PEMBAHASAN}

\section{Rendemen}

Rendemen merupakan perbandingan antara hasil minyak atsiri dengan jumlah bagian kulit jeruk yang digunakan saat distilasi (Harris R, 1994). Minyak atsiri hasil distilasi dilakukan penimbangan berat nya kemudian dibagi dengan berat kering untuk diperoleh nilai rendemen nya (Syauqiah et al., 2008). Rendemen minyak atsiri dapat dipengaruhi oleh faktor waktu distilasi, suhu, tekanan operasi, jenis dan kualitas bahan yang digunakan (Muhtadin et al., 2013).

Hasil perhitungan rendemen minyak atsiri dapat dilihat pada Tabel 1. Minyak atsiri jeruk purut memiliki rendemen yang lebih tinggi dibandingkan dengan minyak atsiri jeruk siam Pontianak. Menurut penelitian Aran et al., (2021), rendemen yang dihasilkan dari distilasi daun jeruk purut adalah sebesar $1,083 \%$. Hal ini menunjukkan jika bagian kulit dari jeruk purut memiliki lebih banyak minyak atsiri.

Tabel 1. Hasil Analisis Rendemen, Bobot Jenis dan Putaran Optik Minyak Atsiri Kulit Jeruk Table 1. Yield, Specific Gravity and Optical Rotation of Orange Peel Essential Oil

\begin{tabular}{lccc}
\hline Jenis Minyak Atsiri & $\begin{array}{c}\text { Rendemen } \\
(\% \mathrm{v} / \mathrm{b})\end{array}$ & $\begin{array}{c}\text { Bobot Jenis } \\
(\mathrm{g} / \mathrm{mL})\end{array}$ & Putaran Optik $\left(^{\circ}\right)$ \\
\hline Jeruk Purut & 4,369 & 0,892 & 11,463 \\
Jeruk Siam Pontianak & 3,161 & 0,824 & 102,464 \\
\hline
\end{tabular}

\section{Bobot Jenis}

Bobot jenis dapat menjadi sebuah indikator untuk menentukan kemurnian dari minyak atsiri (Hidayati, 2012). Bobot jenis atau densitas merupakan massa partikel yang menempati volume tertentu, bobot jenis ditetapkan dengan alat piknometer (Sri Mulyani, 2009). Hasil Analisa bobot jenis pada minyak atsiri kulit jeruk purut dan sim Pontianak dapat dilihat pada Tabel 1.

Minyak astiri jeruk purut memiliki nilai bobot jenis yang lebih tinggi dibandingkan dengan minyak atsiri jeruk siam Pontianak. Secara umum, minyak astiri memiliki bobot jenis rata-rata sebesar 0,696 - 1,119 (Hidayati, 2012). Menurut penelitian Sri Mulyani (2009), minyak atsiri daun jeruk purut memiliki bobot jenis sebesar 0,862 dan minyak kulit buah sebesar 0,895 . Banyaknya senyawa yang terkandung dalam minyak atsiri menentukan besarnya nilai bobot jenis. Semakin banyak senyawa dengan fraksi bobot jenis yang tinggi menyebabkan bobot jenis minyak atsiri tersebut meningkat (Kartika Fitri \& Proborini, 2018).

\section{Putaran Optik}

Putaran optik diukur dengan menggunakan alat polarimeter. Besarnya putaran optik tergantung pada jenis dan konsentrasi senyawa, panjang jalan yang ditempuh sinar melalui senyawa tersebut dan suhu pengukuran (Guenther, 1990). Nilai putaran optik pada minyak atsiri dapat dilihat pada Tabel 1. Minyak astiri jeruk siam Pontianak memiliki nilai putaran optik yang lebih tinggi dibandingkan dengan minyak atsiri jeruk purut. Hal ini diduga karena pada minyak atsiri jeruk siam pontianak terdapat banyak komponen yang mempengaruhi bidang polarisasi. 


\section{Warna}

Mutu fisik minyak atsri juga dipengaruhi oleh warna. Pengujian warna minyak atsiri menggunakan alat colour reader. Pengujian warna ditunjukkan dengan nilai $L^{*}, a^{*}, b^{*}$ dimana $L^{*}$ (lightness) menunjukkan perbedaan antara cerah atau terang dan gelap, a* (redness) menujukkan perbedaan antara merah $\left(\mathrm{a}^{*}\right)$ dan hijau $\left(-\mathrm{a}^{*}\right)$, serta $\mathrm{b}^{*}$ (yellowness) menunjukkan warna antara kuning $\left(+b^{*}\right)$ dan biru (-b*) (Tantri Swandari, Panjisakti Basunanda, 2017).

Minyak atsiri jeruk siam memiliki tingkat kecerahan yang lebih tinggi dibandingan dengan jeruk purut. Hal ini bisa dilihat juga pada Gambar 1, minyak atsiri jeruk siam Pontianak memiliki warna yang bening, sedangkan minyak atsiri jeruk purut cenderung bening kekuningan. Menurut Hidayati (2012), umumnya minyak atsiri berwarna bening, kekuningkuningan, atau kemerah-merahan.

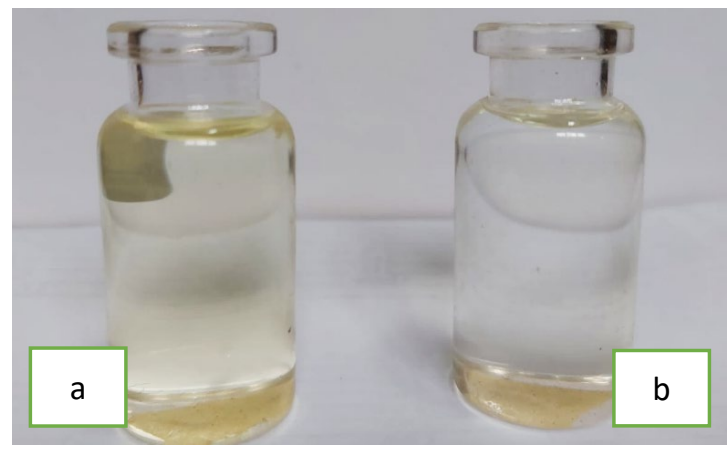

Gambar 1. Minyak atsiri jeruk purut (a), Minyak atsiri jeruk siam Pontianak (b) Figure 1. Kaffir lime essential oil (a), Tangerine Pontianak essential oil (b)

Tabel 2. Hasil Analisis Warna Minyak Atsiri Kulit Jeruk

Table 2. Colour of Orange Peel Essential Oil

\begin{tabular}{lccc}
\hline \multirow{2}{*}{ Jenis Minyak Atsiri } & \multicolumn{3}{c}{ Warna } \\
\cline { 2 - 4 } & $\mathrm{L}^{*}$ & $\mathrm{a}^{*}$ & $\mathrm{~b}^{*}$ \\
\hline Jeruk Purut & 85,15 & 0,67 & $-15,56$ \\
Jeruk Siam Pontianak & 88,92 & 2,72 & $-21,47$ \\
\hline
\end{tabular}

\section{Sensori Kesukaan}

Pengujian sensori kesukaan diperlukan untuk mengetahui penilaian panelis terhadap mutu minyak atsiri. Pada penelitian ini, pengujian sensori kesukaan dilakukan terhadap 30 panelis dengan menilai atribut warna dan aroma. Panelis diminta untuk memberikan penilaian mulai dari sangat suka hingga sangat tidak suka dengan skor nilai 1-5. Semakin tinggi nilai yang diberikan menyatakan jika panelis sangat menyukai minyak atsiri pada astibut tersebut. Hasil pengujian sensori kesukaan pada minyak atsiri kulit jeruk dapat dilihat pada Tabel 3.

Panelis lebih menyukai warna dan aroma dari minyak atsiri jeruk siam pontianak dibandingkan dengan minyak atsri jeruk purut. Hal ini diduga karena minyak atsiri jeruk siam Pontianak memiliki warna yang cenderung lebih bening apabila dibandingkan dengan atsiri jeruk purut. hal ini bisa dilihat pada Gambar 1. Senyawa aromatik yang terkadung dalam kulit jeruk itu berbedabeda, tergantung dari varietasnya (Hidayati, 2012). Atsiri kulit jeruk siam Pontianak cenderung memiliki aroma yang lebih segar dibandingkan dengan atsiri kulit jeruk purut. diduga hal ini disebabkan karena kandungan limonin pada minyak atsiri jeruk siam Pontianak yang lebih tinggi. Limonene memiliki aroma jeruk yang sangat kuat (Gualdani et al., 2016) . 
Tabel 3. Hasil Analisis Sensori Kesukaan Minyak Atsiri Kulit Jeruk

Table 3. Sensory Evaluation of Orange Peel Essential Oil

\begin{tabular}{lcc}
\hline Jenis Minyak Atsiri & Warna & Aroma \\
\hline Jeruk Purut & 3,050 & 3,550 \\
Jeruk Siam Pontianak & 3,600 & 4,050 \\
\hline
\end{tabular}

\section{Kandungan Senyawa Volatil}

Senyawa volatil yang terkandung pada minyak atsiri dapat diidentifikasi menggunakan GC-MS (Das et al., 2014). Hasil Analisa kandungan senyawa volatil pada minyak atsiri kulit jeruk dapat dilihat pada Tabel 4. Pada minyak atsiri jeruk purut terdapat 9 senyawa yang teridentifikasi. Senyawa yang ditemukan dengan konsentrasi tertinggi adalah limonin sebesar 24,325\% dan sabiene sebesar 15,137\%. Menurut penelitian Iryani \& Deka (2018) minyak atsiri kulit jeruk purut mengandung senyawa limonin sebesar $16,45 \%$ dan sabinene sebesar $11,13 \%$.

Minyak atsiri jeruk purut memiliki jumlah senyawa teridentifikasi yang lebih banyak dibandingkan dengan minyak atsiri jeruk siam Pontianak. Hal ini diduga menyebabkan minyak atsiri jeruk purut memiliki bobot jenis yang lebih tinggi (Tabel 1).

Minyak atsiri kuit jeruk siam Pontianak mengandung 4 senyawa yang teridentifikasi menggunakan GC-MS. Senyawa yang tertinggi adalah limonin sebesar 91,840\%. Kandungan limonin yang tinggi pada minyak atsiri jeruk siam Pontianak ini sesuai dengan hasil kesukaan aroma pada pengujian sensori nya yang dapat dilihat pada Tabel 3. Salah satu komponen pembentuk aroma pada minyak atsiri adalah limonin (Minh Tu et al., 2003). Minyak atsiri kulit jeruk siam memiliki kandungan senyawa seperti limonin 97,69\%, linalool $0,56 \%$ dan pinene 0,41\%. (Hidayati, 2012).

Tabel 4. Hasil Analisis GC-MS Kandungan Senyawa Volatil dalam Minyak Atsiri Kulit Jeruk

Table 4. Volatile Components of of Orange Peel Essential Oil

\begin{tabular}{lcc}
\hline \multirow{2}{*}{ Nama Senyawa } & \multicolumn{2}{c}{ Konsentrasi Senyawa Volatil (\%) } \\
\cline { 2 - 3 } & Jeruk Purut & Jeruk Siam Pontianak \\
\hline -Pinene & $2,681 \%$ & - \\
Beta pinene & - & $2,215 \%$ \\
Limonen & $24,325 \%$ & $91,840 \%$ \\
Beta-Phellandrene & $12,820 \%$ & $0,842 \%$ \\
Linalool & - & $0,811 \%$ \\
Sabiene & $15,137 \%$ & - \\
Citronella & $7,743 \%$ & - \\
Beta-Citronellol & 6,838 & - \\
Isopulegeol & $0,266 \%$ & - \\
Cadiene & $0,552 \%$ & - \\
Gamma-terpiene & $1,282 \%$ & - \\
\hline
\end{tabular}




\section{KESIMPULAN}

Rendemen minyak atsiri yang tertinggi diperoleh dari distilasi kulit jeruk purut yaitu sebesar 4,369\%. Minyak atsiri kulit jeruk purut memiliki nilai bobot jenis yang lebih tinggi dibandingkan dengan minyak atsiri jeruk siam Pontianak, namun memiliki nilai putaran optik yang lebih rendah. Panelis lebih menyukai warna dan aroma dari minyak atsiri jeruk siam Pontianak. Kedua sampel minyak atsiri mengandung senyawa limonin dengan kadar yang berbeda.

\section{DAFTAR PUSTAKA}

Aran, D. H., Mariani, Y., \& Yusro, F. 琶 (2021). Minyak Atsiri Daun Jeruk Purut (Citrus Hystrix) Dan Bioaktivitasnya Terhadap Bakteri Propionibacterium acnes DAN Pseudomonas aeruginosa. Bioma: Jurnal Biologi Dan Pembelajaran Biologi, 6(1), 1-10.

Arce, A., Marchiaro, A., Martínez-Ageitos, 琶 J. M., \& Soto, A. (2005). Citrus essential oil deterpenation by liquidliquid extraction. Canadian Journal of Chemical Engineering, 83(2), 366-370.

Das, D. R., Sachan, A. K., Shuaib, M., \& 尌 Imtiyaz, M. (2014). Chemical Charecterization of Volatile Oil Components of Citrus Reticulata By Gc-Ms Analysis. 3(6), 1197-1204.

Espina, L., Somolinos, M., Lorán, S., 䁌 Conchello, P., García, D., \& Pagán, R. (2011). Chemical composition of commercial citrus fruit essential oils and evaluation of their antimicrobial activity acting alone or in combined processes. Food Control, 22(6), 896902.
Fekadu, T., Seifu, T., \& Abera, A. (2019).

Extraction of Essential Oil from Orange Peel using Different Methods and Effect of Solvents, Time, Temperature to Maximize Yield Green synthesis of nanoparticles View project Extraction of essential oil View project Extraction of Essential Oil from Orange. International Journal of Engineering Science and Computing, 9(March), 24300-24308.

Gualdani, R., Cavalluzzi, M. M., Lentini, 臸 G., \& Habtemariam, S. (2016). The chemistry and pharmacology of citrus limonoids. In Molecules (Vol. 21, Issue 11).

Harris R. (1994). Tanaman Minyak Atsiri. 豇 In Penebar Swadaya.

Hidayati. (2012). Distilasi Minyak Atsiri 僉 dari Kulit Jeruk Pontianak dan Pemanfaatannya dalam Pembuatan Sabun Aromaterapi. Biopropal Industri, 3(2), 39-49.

Honestin, T., Ikarini, I., Ashari, H., \& Elanif, Z. (2020). Pengaruh Sari Jeruk Siam Pontianak dan Keprok Terigas terhadap Kualitas Es Krim. Prosiding Seminar Nasional Lahan Suboptimal Ke-8 Tahun 2020, Palembang 20 Oktober 2020 “, 978979.

Ikarni, I., Honestin, T., Ashari, H., \& 㰯 Hanif, Z. (2020). Karakteristik Minuman Sari Jeruk Keprok Terigas dengan Penambahan beberapa Jenis Penstabil. Prosiding Seminar Nasional Lahan Suboptimal Ke-8 Tahun 2020, Palembang 20 Oktober 2020 “, 978-979. 
Iryani, A. S., \& Deka, A. (2018).

琹 Pembuatan Minyak Atsiri Dari Kulit Jeruk Purut (Citrus Histrix) Dengan Metode Ekstraksi. Prosiding Seminar Hasil Penelitian, 978-60260, 159-161.

Kartika Fitri, A. C., \& Proborini, W. D. 的 (2018). Analisa Komposisi Minyak Atsiri Kulit Jeruk Manis Hasil Ekstraksi Metode Microwave Hydrodiffusion and Gravity Dengan Gc-Ms. Reka Buana: Jurnal Ilmiah Teknik Sipil Dan Teknik Kimia, 3(1), 53.

Kurniawan, A., Chandra, Indraswati, N., \& 钢 Mudjijati. (2008). Ekstraksi Minyak Kulit Jeruk Dengan Metode Distilasi, Pengepresan dan Leaching. Widya Teknik, 7(1), 15-24.

Mani-López, E., Lorenzo-Leal, A. C., 钢 Palou, E., \& López-Malo, A. (2017). Principles of Sensory Evaluation in Foods Containing Essential Oil. Essential Oils in Food Processing. Chemistry, Safety and Applications, 293-325.

Minh Tu, N. T., Onishi, Y., Choi, H. S., 钢 Kondo, Y., Ukeda, H., \& Sawamura, M. (2003). Characteristic odour components of Citrus sp. (Kiyookadaidai) cold-pressed peel oil. Flavour and Fragrance Journal, 18(6), 515-520.

Muhtadin, A. F., Wijaya, R., \& Prihatini, P. 琶 (2013). Pengambilan Minyak Atsiri dari Kulit Jeruk. Jurnal Teknik Pomits, 2(1), 98-101.

Sawamura, M., Onishi, Y., Ikemoto, J., Tu, 钢 N. T. M., \& Phi, N. T. L. (2006). Characteristic odour components of bergamot (Citrus bergamia Risso) essential oil. Flavour and Fragrance Journal, 21(4), 609-615.
Sri Mulyani, S. dan M. M. H. (2009).

钢 Analisis GC-MS dan daya anti bakteri minyak atsiri Citrus amblycarpa ( Hassk ) Ochse Antibacterial activity and GC-MS analysis of the Citrus. Majalah Farmasi Indonesia, 20(3), 127-132.

Syauqiah, I., Mirwan, A., Sulaiman, A., \& 显 Nurandini, D. (2008). Analisis Pengaruh Lama Penyulingan dan Komposisi Bahan Baku Terhadap Rendemen dan Mutu Minyak Atsiri dari Daun dan Batang Nilam. InfoTeknik, 9(1), 21-30.

Tantri Swandari, Panjisakti Basunanda, A. EQ P. (2017). Tantri Swandari et al. : Penggunaan Alat Sensor Warna untuk Menduga Derajat Dominasi Gen Penyadi Karakter Warna Buah Cabai Hasil Persilangan. Agroista, 1(2), 1-10. 